\title{
Assessing the impact of climate change on extreme fire weather events over southeastern Australia
}

\author{
A. E. A. Hasson ${ }^{1,3}$, G. A. Mills ${ }^{1,2}$, B. Timbal ${ }^{1, *}$, K. Walsh $^{3}$ \\ ${ }^{1}$ Centre for Australian Weather and Climate Research, GPO 1289, Melbourne, Victoria 3001, Australia \\ ${ }^{2}$ Bushfire Cooperative Research Centre, Level 5, 340 Albert Street, East Melbourne, Victoria 3002, Australia \\ ${ }^{3}$ School of Earth Sciences, University of Melbourne, Swanston Street, Melbourne, Victoria 3010, Australia
}

\begin{abstract}
Extreme fire weather events in southeastern Australia are frequently associated with strong cold fronts moving through the area. A recent study has shown that the $850 \mathrm{hPa}$ temperature and the magnitude of its gradient over a small region of southeastern Australia provide a simple means of discriminating the most extreme cold frontal events during the last $40 \mathrm{yr}$ from reanalysis data sets. Applying this technique to 10 general circulation models (GCMs) from the Coupled Model Intercomparison Project and calibrating the temperature gradient and temperature climatology of each model's simulation of the climate of the 20th century against the reanalysis climates allows estimates of likely changes in frequency of this type of extreme cold front in the middle and end of the 21st century. Applying this analysis to the output of 10 GCM simulations of the 21st century, using low and high greenhouse gas emissions scenarios, suggests that the frequency of such events will increase from around 1 event every 2 yr during the late 20th century to around 1 event per year in the middle of the 21st century and 1 to 2 events per year by the end of the 21st century; however, there is a great degree of variation between models. In addition to a greater overall increase under the high emissions scenario, the rate at which the increase occurs amplifies during the second half of the century, whereas under the low emissions scenario the number of extreme cases stabilizes, although still at a higher rate than that experienced in the late 20th century.
\end{abstract}

KEY WORDS: Fire weather $\cdot$ Climate change $\cdot$ Strong cold front

\section{INTRODUCTION}

Over recent years, and with increased emphasis since the release of the 4th Assessment Report (AR4) of the Intergovernmental Panel on Climate Change (IPCC) in 2007 (IPCC 2007), there has been intense interest in likely trends in extreme weather events due to the anticipated changes in climate. There has long been particular concern about the severity of future fire seasons in southern Australia, where the expected trend in rainfall is negative and in temperature is positive (CSIRO \& Bureau of Meteorology 2007), and where recent summers have seen disastrous levels of wildfire activity. Several studies have attempted to assess the likely severity of fire seasons in Australia under future climate scenarios, including those of Williams et al. (2001), Hennessy et al. (2005), Pitman et al. (2007) and Lucas et al. (2007). Because there is a limited range of variables and frequency of output from the general circulation models (GCMs) relied on for climate change simulations, measures of daily fire danger, such as the forest fire danger index (FFDI, Luke \& McArthur 1978), cannot be calculated as a daily time series. Accordingly, the measures used in these studies generally relate the current statistical distribution of fire weather indices mapped onto broad measures of changed climates and conclude that during the 21st century there will be a clear increase in severity of fire seasons as measured by duration and number of days for which very high and extreme FFDI is expected.

A particular feature of the fire weather climate of southern South Australia, Victoria and Tasmania are the rare, extreme fires such as the Hobart fires in February 1967 (Bond et al. 1967), Ash Wednesday 1983 
(Bureau of Meteorology 1984), the Canberra fire in January 2003 (McLeod 2003) or the Lower Eyre Peninsula fires of 11 January 2005 (Bureau of Meteorology 2005). These have enormous social and economic consequences, yet only occur on a few days each decade.

In a retrospective study of the meteorology of the Ash Wednesday 1983 fires, Mills (2005a) showed that many of the most extreme fire events in southeastern Australia over the $40 \mathrm{yr}$ to the end of the 2003 summer, and 80\% of the bushfire-related deaths during that period, occurred on days on which the magnitude of the east-west $850 \mathrm{hPa}$ temperature gradient in a small rectangle over southeastern Australia was in the highest $0.3 \%$ of its distribution. These calculations were based on the National Centers for Environmental Prediction/National Center for Atmospheric Research (NCEP/NCAR) reanalysis (NNR) data set (Kalnay et al. 1996) using analyses at 00:00 and 12:00 UTC for the summer months. It was argued that while this measure of synoptic severity did not identify a unique weather element sequence at any location, it did indicate a strong front. The orientation of the southeast Australian coastline, a hot, continental air mass inland and the cooler maritime air mass over the Southern Ocean leads to an intensification of cold fronts as they approach and interact with the coastal temperature gradient of southeast Australia. As these fronts intensify, the development of a northerly pre-frontal jet advects hot, dry gusty winds southwards - all the ingredients for extreme fire weather (Luke \& McArthur 1978). In addition, the wind-shift associated with these fronts can cause the flank of a fire to become a much longer head-fire, and this effect is exacerbated if there is sufficient depth of cold air following these fronts to maintain strong, gusty, post-frontal winds that can greatly enhance fire spread (Cheney et al. 2001, Mills 2005a).

As GCM output routinely includes the $850 \mathrm{hPa}$ temperature field, the fact that the $850 \mathrm{hPa}$ temperature gradient is such a simple calculation makes the potential application to climate change models of Mills (2005a) analysis worth investigating. The premise is that if there is a change in the frequency of these strong temperature gradient events under climate change simulations, then this would translate to a change in the frequency of the type of strong cold front that Mills (2005a) associated with extreme fire weather events. To address this question a number of steps need to be taken. First, Mills (2005a) only used the NNR data set, so the same calculations are performed based on the European Centre for Medium Range Weather Forecasts 40 yr reanalysis data (ERA-40; Kallberg et al. 2005) to demonstrate that the methodology is robust to choice of reanalysis data set. Second, output fields from the GCM archived within Phase 3 of the Coupled Model Intercomparison Project (CMIP3) database used in the present study were only available at 00:00 UTC, rather than the 00:00 and 12:00
UTC used by Mills (2005a); we show that applying the technique to reanalysis data sets valid only at 00:00 UTC still provides discrimination of the extreme fire events. These aspects are addressed in the following section.

In the following section the application of the method to GCMs, and in particular the manner in which the temperature gradient calculations were made, is assessed. The models are validated against the reanalyses to evaluate their temperature gradient climatology for the latter decades of the 20th century. Finally, the resulting projected changes in the frequency of strong cold fronts for the middle and the latter part of the 21st century are described, and the results summarised.

\section{DATA}

\subsection{Reanalysis data}

Both the NNR and ERA-40 data sets are available on the same $2.5 \times 2.5^{\circ}$ horizontal grid (although the model used in the generation of the ERA-40 data had a native grid of $1.8 \times 1.8^{\circ}$ ), and at a number of pressure levels, including $850 \mathrm{hPa}$. Mills (2005a) used NNR data from 1964-2003 inclusive, but in the present study the period of analysis is restricted to 1 January 1964 to 28 February 2002, the last date available for the ERA-40 analyses.

\subsection{Climate model data sets}

Temperature fields from 10 coupled atmosphereocean GCMs from the CMIP3 used in the recent IPCC AR4 (IPCC 2007) were available for the present study. These are listed in Table 1; more details of the configurations of these models can be found in IPCC (2007). Data were only available at $24 \mathrm{~h}$ intervals, and valid at 00:00 UTC. For each model the period 1960-1999 was used to represent the climate of the 20th century (C20C) for comparison with the reanalysis climates, while the periods 2046-2065 and 2081-2100 were used to assess changes that might be discernable by the middle and late 21st century. As part of the IPCC AR4, a range of emissions scenarios were used to force the GCMs and provide estimates of a range of possible climate projections (IPCC 2000). For the present study, 2 of these projections were used, 1 each corresponding to one of the higher (A2) and one of the lower (B1) emissions growth scenarios. The A2 (B1) scenario leads to a global average temperature rise of some 2.0 to $5.4^{\circ} \mathrm{C}\left(1.1\right.$ to $\left.2.9^{\circ} \mathrm{C}\right)$ by the end of the 21st century (IPCC 2007). For each scenario the range of possible warming indicates the differing sensitivities of the individual climate models to these external forcings. A measure of the sensitivity of the individual GCMs used in the present study is indicated in 
Table 1. List of acronyms used for IPCC AR4 coupled models, the nation where they were developed and their resolution. Temperature change indicates the change in temperature between 1980-1999 and 2090-2099 for each model under the A1B emissions scenario

\begin{tabular}{|llcc|}
\hline Acronym & Nation & $\begin{array}{c}\text { Grid } \\
\text { spacing }\left({ }^{\circ}\right)\end{array}$ & $\begin{array}{c}\text { Temperature } \\
\text { change }\left({ }^{\circ} \mathrm{C}\right)\end{array}$ \\
\hline CCM & Canada & $3.8 \times 3.8$ & 2.47 \\
CNRM & France & $2.8 \times 2.8$ & 2.81 \\
CSIRO & Australia & $1.9 \times 1.9$ & 2.11 \\
GFDL1 & USA & $2.5 \times 2.0$ & 2.98 \\
GFDL2 & USA & $2.5 \times 2.0$ & 2.53 \\
GISSR & USA & $5.0 \times 4.0$ & 2.12 \\
IPSL & France & $3.7 \times 2.5$ & 3.19 \\
MIROC & Japan & $2.8 \times 2.8$ & 3.35 \\
MPI & Germany & $1.9 \times 1.9$ & 3.69 \\
MRI & Japan & $2.8 \times 2.8$ & 2.57 \\
\hline
\end{tabular}

the right-hand column of Table 1, where the global mean temperature rise for each model forced by the A1B emission scenario (the closest to the mean of the scenarios considered) and approximated by linear regression over the 21st century (CSIRO \& Bureau of Meteorology 2007 , their Table 4.1) is shown.

\subsection{Extreme fire event data}

The quality, temporal consistency and content of fire event and/or activity databases in Australia is rather varied, and this makes it difficult to quantitatively relate fire activity or occurrence to purely meteorolog- ical features. In addition, the probability of an ignition occurring is unknown, and the effectiveness of mitigation efforts affects the subsequent fire behaviour and consequences. Mills (2005a) used published reports as an indicator of the socioeconomic impacts of a fire, with the assumption that only 'significant' fires subsequently lead to documented post-event studies. That study did not attempt to develop a causal relationship between the temperature/temperature gradient at $850 \mathrm{hPa}$ and fire activity, but did match published reports and documented bushfire-related deaths to the 30 strongest temperature gradient days in the $40 \mathrm{yr}$ NNR data set analysed to demonstrate that these days included a disproportionate number of major fire events and fatalities. In the present study we use the fire event data in a similar way - to qualitatively indicate the robustness of the analysis technique to choice of reanalysis data set, and to support the hypothesis that changes in frequency of the strongest cold fronts is likely to lead to an increase in damaging fire events.

The restriction of our comparison between the reanalyses to the period of the ERA-40 data set precludes using the fire events in the 2002-2003 summer (Mills 2005a, their Tables 1 \& 2), which made some of the Mills (2005a) event days unavailable for comparison with the ERA-40 data. A few other event days have been added, based on fire agency web-based data sets, and these are indicated in Table 2. These data are only used in the comparison of the NNR and ERA-40 data, as the GCMs generate their own daily weather succession that cannot be compared directly with the observed succession.

Table 2. List of fire events in southeast (SE) Australia over 1964-2000, adapted from Mills (2005a), featuring for each fire event its location, date, values of the 00:00 UTC maximum thermal gradient $\left(T_{\mathrm{G}}\right)$ and maximum temperature $\left(T_{\max }\right)$ from NNR and ERA-40 data sets and from the ERA-40 modified data set as described in the text. ${ }^{a}$ Events not listed in Mills (2005a), bevent points in

Fig. $4 \mathrm{~b}$ that have relatively high temperatures but $T_{\mathrm{G}}$ values $<2.5 \mathrm{~K}$. NSW: New South Wales; SA: South Australia

\begin{tabular}{|c|c|c|c|c|c|c|c|c|c|}
\hline \multirow[t]{2}{*}{ Location } & \multicolumn{3}{|c|}{ Date } & \multicolumn{2}{|c|}{ NNR } & \multicolumn{2}{|c|}{ ERA-40 } & \multicolumn{2}{|c|}{ ERA-40 modified } \\
\hline & $(\mathrm{yr})$ & $(\mathrm{mo})$ & (d) & $T_{\mathrm{G}}$ & $T_{\max }$ & $T_{\mathrm{G}}$ & $T_{\max }$ & $T_{\mathrm{G}}$ & $T_{\max }$ \\
\hline Longwood & 1965 & 1 & 17 & 2.11 & 296.2 & 3.36 & 295.9 & 3.61 & 295.3 \\
\hline Brigalong $^{\mathrm{a}, \mathrm{b}}$ & 1965 & 2 & 22 & 3.27 & 292.2 & 1.56 & 298.3 & 2.70 & 292.1 \\
\hline Hobart $^{\mathrm{b}}$ & 1967 & 2 & 7 & 3.26 & 296.0 & 1.77 & 295.4 & 2.58 & 294.5 \\
\hline SE Australia fires ${ }^{b}$ & 1968 & 1 & 31 & 2.85 & 298.3 & 2.08 & 292.1 & 2.91 & 296.5 \\
\hline Yarra Junction $^{\text {b }}$ & 1972 & 12 & 2 & 3.86 & 293.1 & 1.38 & 294.9 & 2.74 & 287.9 \\
\hline Western District ${ }^{\mathrm{a}, \mathrm{b}}$ & 1976 & 1 & 3 & 3.01 & 297.0 & 1.75 & 292.2 & 2.46 & 296.1 \\
\hline Streatham & 1977 & 2 & 12 & 3.18 & 295.6 & 2.88 & 294.9 & 2.88 & 294.9 \\
\hline Paynesville & 1978 & 1 & 15 & 3.79 & 298.7 & 3.01 & 292.2 & 3.01 & 292.2 \\
\hline Caroline Forest & 1979 & 2 & 3 & 3.33 & 293.8 & 3.05 & 294.6 & 3.05 & 294.6 \\
\hline Mallee & 1981 & 1 & 3 & 3.20 & 297.9 & 3.45 & 297.0 & 3.48 & 297.0 \\
\hline Central Victoria & 1982 & 1 & 11 & 2.54 & 297.1 & 2.91 & 295.9 & 2.91 & 295.9 \\
\hline Yallourn & 1982 & 1 & 24 & 3.21 & 302.1 & 3.29 & 300.8 & 3.29 & 300.8 \\
\hline Wombat State Forest $^{\mathrm{a}}$ & 1983 & 1 & 9 & 3.27 & 291.1 & 3.47 & 291.3 & 3.47 & 291.3 \\
\hline SE Australia (Ash Wednesday) & 1983 & 2 & 16 & 2.35 & 298.8 & 3.00 & 298.6 & 3.73 & 286.3 \\
\hline SE Australia, 33 fires $^{\mathrm{a}, \mathrm{b}}$ & 1984 & 2 & 26 & 2.88 & 292.5 & 2.03 & 289.0 & 4.00 & 292.3 \\
\hline Central Victoria & 1985 & 1 & 14 & 2.92 & 299.7 & 3.27 & 297.8 & 3.27 & 297.8 \\
\hline SE Australia, 132 fires & 1990 & 1 & 3 & 3.49 & 299.5 & 3.51 & 298.1 & 3.51 & 298.1 \\
\hline Tasmania & 1996 & 12 & 25 & 2.98 & 289.5 & 3.37 & 288.0 & 3.37 & 288.0 \\
\hline NSW/Tasmania ${ }^{\mathrm{a}}$ & 1997 & 12 & 21 & 2.77 & 294.9 & 3.01 & 294.0 & 3.01 & 294.0 \\
\hline SA/Mt. Macedon & 1998 & 2 & 26 & 3.31 & 299.2 & 3.72 & 299.0 & 3.72 & 299.0 \\
\hline
\end{tabular}




\section{COMPARISON OF REANALYSES}

Mills (2005a) characterised the synoptic character of an extreme fire weather day over southeastern Australia by the maximum value of the $850 \mathrm{hPa}$ temperature gradient $\left(T_{\mathrm{G}}\right)$ at the reanalysis gridpoints over a small subsection $\left(35-40^{\circ} \mathrm{S}, 135-150^{\circ} \mathrm{E}\right)$ of the analysis domain; hereafter termed the 'gradient box'. This is shown in Fig. 1 overlaid on the NNR $850 \mathrm{hPa}$ temperature field for the evening of the Ash Wednesday fires in 1983. The elongated gradient box was chosen so that if an eastward-moving frontal zone was located somewhere in the gradient box, then a high value of the temperature gradient would be diagnosed; it was argued in Mills (2005a) that using reanalyses every $12 \mathrm{~h}$ was sufficient to capture most events. It was also noted that many of the major fire events were associated with stronger east-west than north-south temperature gradients: that is, more meridionally-oriented isotherms. It was proposed that a parameter that identified these events was the highest temperature on the east-west grid row through the middle of the gradient box, termed $T_{\max }$. Mills (2005a) argued that the high
$T_{\mathrm{G}}$ /high $T_{\max }$ area of the entire $T_{\mathrm{G}} / T_{\max }$ phase space included the major events listed, and so discriminates such events (Mills 2005a, their Fig. 16).

Fig. 2 shows the synoptic patterns associated with the 8 strongest gradient 'documented event' days from Mills (2005a, their Table 1), excluding the events after the end of the ERA-40 data, from the ERA-40 analyses. These show the mean sea level pressure and $850 \mathrm{hPa}$ isotherms, and in all cases there is a marked thermal ridge and a marked baroclinic zone over southeast Australia associated with the passage of a surface trough. As noted in Mills (2005a), there is sufficient case-to-case variation to mean that the particular surface weather sequence at any location will differ from case to case, but the strong $850 \mathrm{hPa}$ thermal pattern is common. Other more recent cases are documented in Mills (2005b, 2008) and Hasson et al. (2008).

Since the publicly available NNR and ERA-40 datasets have the same spatial discretisation, identical gradient boxes over southeast Australia can be used to calculate $T_{\mathrm{G}}$ and $T_{\max }$. Fig. 3 shows the $T_{\mathrm{G}}$ versus $T_{\max }$ scatter plots for the NNR and ERA-40 data sets with both 12:00 and 00:00 UTC analyses included, and with

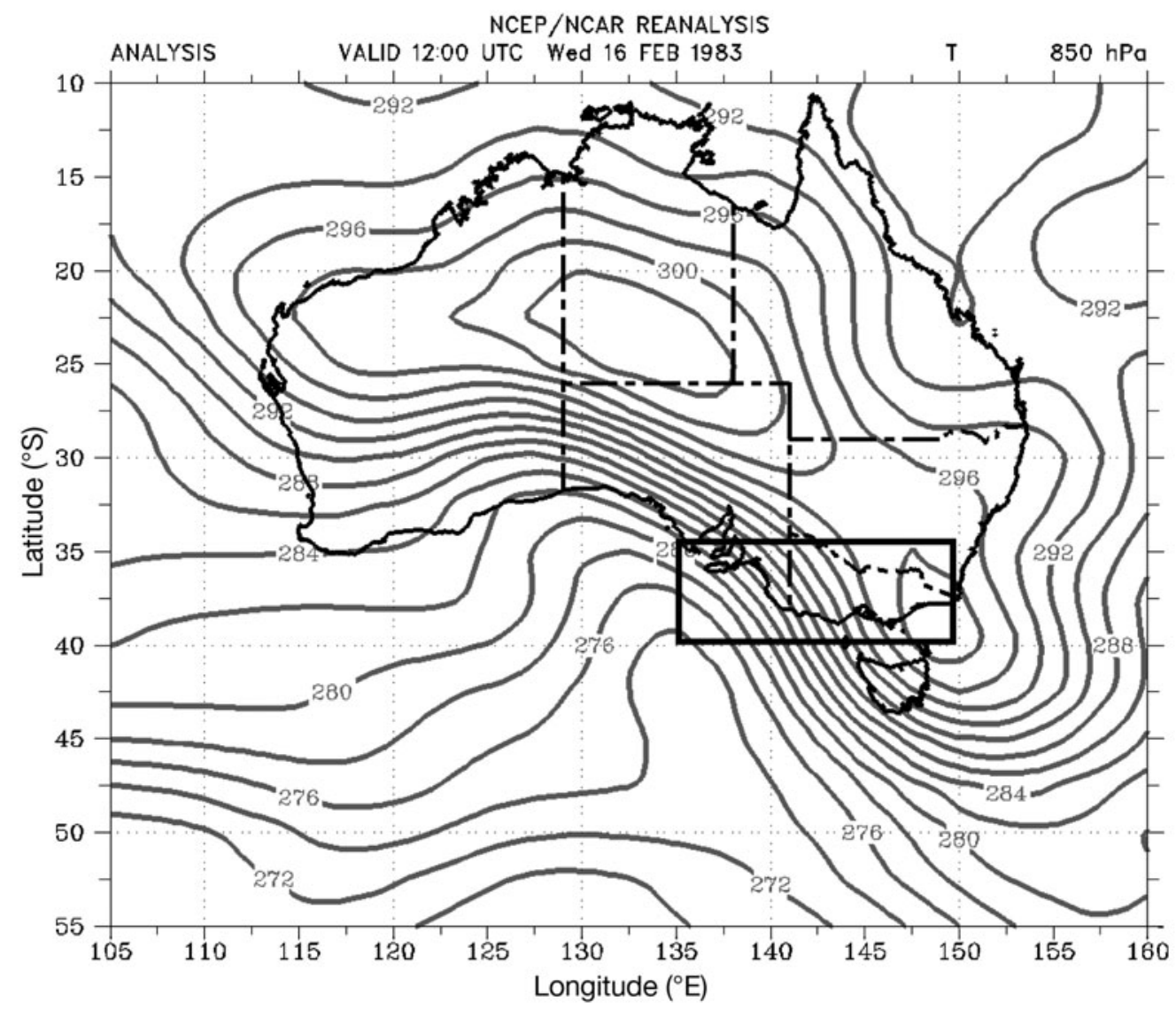

Fig. 1. Temperature field (K) at $850 \mathrm{hPa}$ at 12:00 UTC 16 February 1983 from the NCEP/NCAR reanalysis data set. The rectangle marks the gradient box used in the calculation described in the present study 

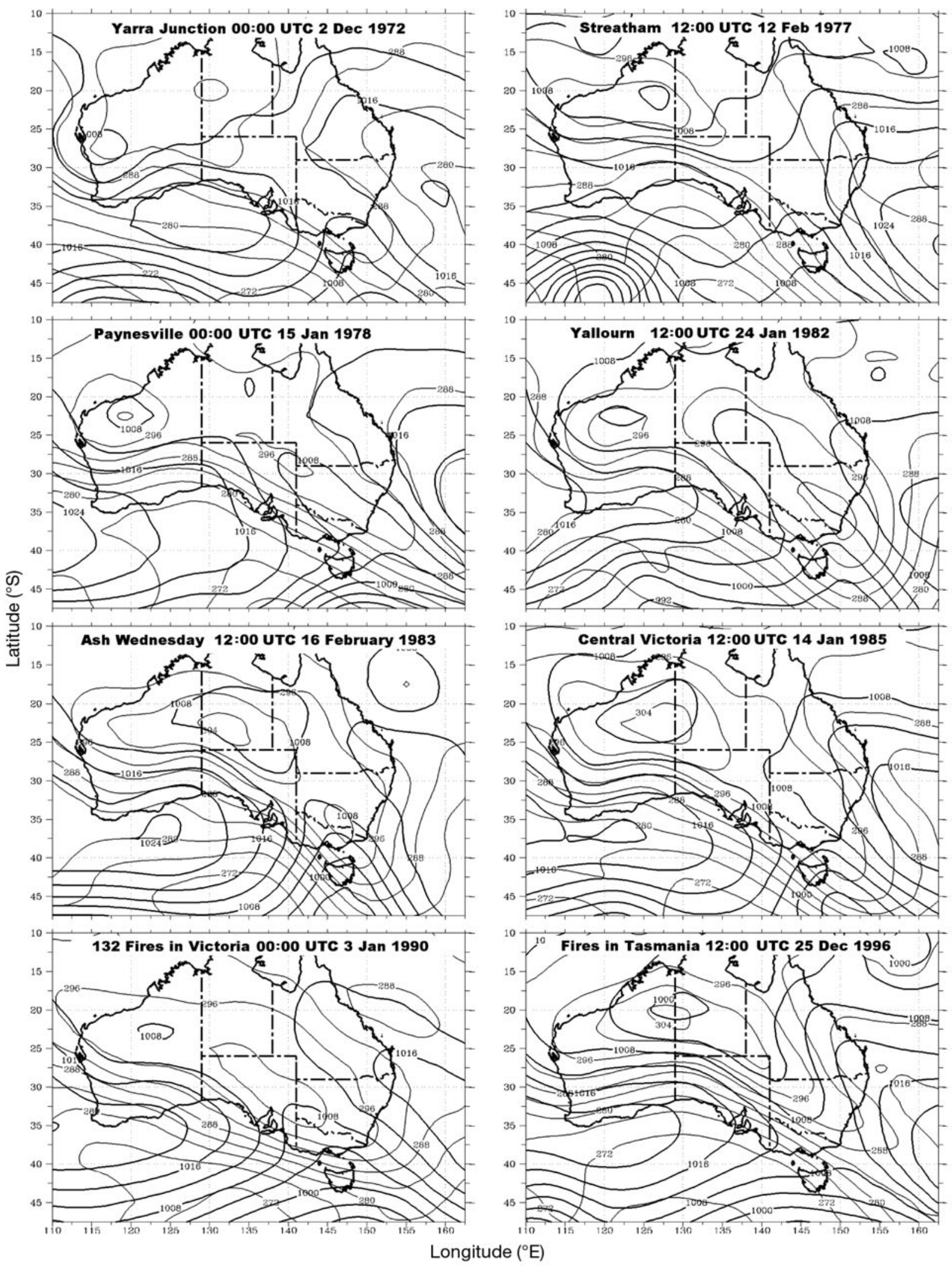

Fig. 2. ERA-40 analyses of 8 fire events in southeast Australia associated with strong 850 hPa temperature gradients. Black contours: mean sea level pressure (MSLP), contour interval $4 \mathrm{hPa}$; gray contours: $850 \mathrm{hPa}$ temperature, contour interval $4 \mathrm{~K}$. The descriptors are those used in Table 1 of Mills (2005a) 

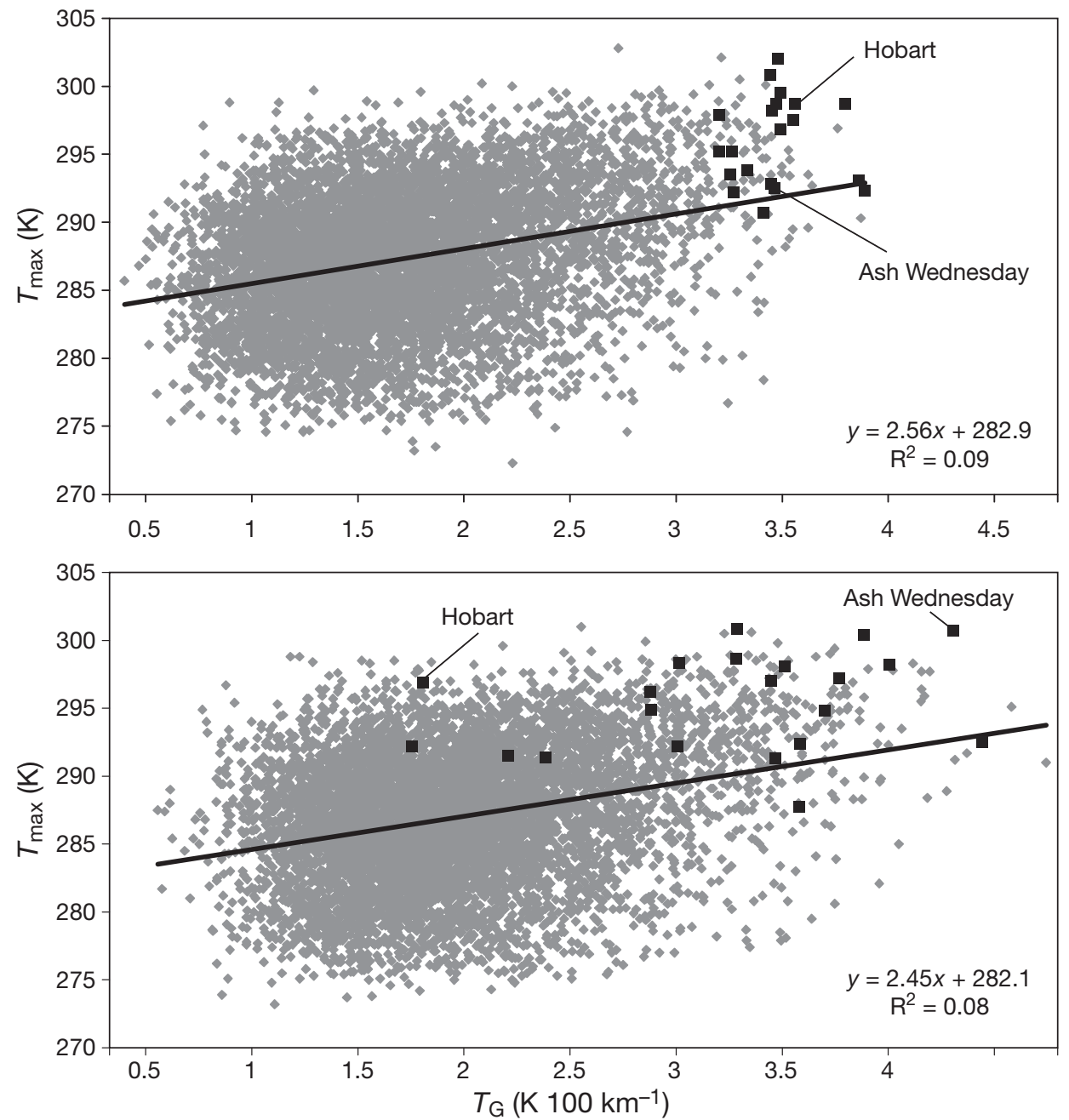

Fig. 3. Scatter plot and its linear regression of the $850 \mathrm{hPa}$ maximum thermal gradient $\left(T_{\mathrm{G}}\right)$ versus the maximum temperature $\left(T_{\max }\right)$ on $37.5^{\circ} \mathrm{S}$ over the Victorian Box at 00:00 and 12:00 UTC during summer for the period 1964-2002 for the NNR (top) and ERA-40 data sets (bottom). The squares are for the events listed in Table 2 the event dates shown in Table 2 highlighted. For NNR, the events cluster strongly in the top right-hand sector of the distribution, as seen in Mills (2005a). While there is a greater degree of scatter in the events in the ERA-40 data set, there is still a strong bias to higher temperatures and an indication of enhanced event frequency towards the stronger gradients.

The IPCC climate model datasets available for our later analysis of the 21st century simulations were only available at $24 \mathrm{~h}$ intervals, valid at 00:00 UTC (11:00 h Eastern Australia Summer Time). Applying the analysis to only 00:00 UTC reanalysis data on the day of the fire leads to a considerably greater scatter of the event data (Hasson et al. 2008, their Figs. 13-15). However, with the normal diurnal variation of fire activity peaking in the afternoon, this result is perhaps to be expected. Sampling may also contribute to this result, as the eastward movement of a frontal system may well mean that with 1 sample per day the major thermal gradient may not lie within the gradient box at 00:00 UTC, particularly as land-sea thermal gradients will also be stronger later in the day. These issues are ameliorated if the highlighted event points are matched to the higher $T_{\mathrm{G}}$ value either at 00:00 UTC on the calendar day of the fire event, or on the subsequent 00:00 UTC analysis; this analysis is shown in Fig. 4. There is a clear clustering of the event points towards the high $T_{\mathrm{G}}$ /high $T_{\max }$ zone of the phase diagrams.

An alternative way of illustrating this point is to look more closely at the 6 event points in Fig. 4b that have relatively high temperatures but $T_{\mathrm{G}}$ values $<2.5 \mathrm{~K}$ $100 \mathrm{~km}^{-1}$. These events are marked ' $\mathrm{b}$ ' in Table 2, which lists, for each event, the 00:00 UTC values of $T_{\mathrm{G}}$ and $T_{\max }$ for NNR and ERA-40 on the calendar day of the fire event, and also those values at 00:00 UTC on the following day for ERA-40 (ERA-40 modified). Each of these highlighted events shows a higher $T_{\mathrm{G}}$ value at 00:00 UTC on the day following the date of the fire event, although on only 2 of those 6 days was $T_{\max }$ also higher. This is consistent with the eastward movement of a frontal system such that a baroclinic zone further east in the gradient box would be more likely to have a lower $T_{\max }$ than one in the western part of the gradient box. 
Fig. 4. Scatter plot and its linear regression of the $850 \mathrm{hPa}$ maximum thermal gradient $\left(T_{\mathrm{G}}\right)$ versus the maximum temperature $\left(T_{\max }\right)$ on $37.5^{\circ} \mathrm{S}$ over the Victorian Box at 00:00 UTC during summer for the period 1964-2002 for the NNR (top) and ERA-40 data sets (bottom). The squares are for the events listed in Table 2, with the higher of the 00:00 UTC $T_{\mathrm{G}}$ values for the listed (Table 2) and $24 \mathrm{~h}$ following dates highlighted

It thus appears that, while less satisfactory than having a $12 \mathrm{~h}$ interval between analyses, applying this technique to a time sequence of analyses at $24 \mathrm{~h}$ intervals does still show a clear association with extreme fire events over southeastern Australia. This is an important result in the context of the present study, as it makes it possible to apply the technique to the CMIP3 data set, for which only 00:00 UTC data are readily available. The hypothesis can thus be developed that thresholds for $T_{\mathrm{G}}$ and $T_{\max }$ may be specified such that if each is exceeded, then the part of the phase space that exceeds both thresholds determines the environments of this paradigm of extreme fire weather environments in southeastern Australia. Thresholds for the NNR data that that include all the fire events based on Fig. 3a are $290 \mathrm{~K}$ for $T_{\max }$ and $3.2 \mathrm{~K} 100 \mathrm{~km}^{-1}$ for $T_{\mathrm{G}}$.

\section{APPLICATION TO CLIMATE CHANGE MODELS}

Any changes with time in the number of events exceeding the joint thresholds may be interpreted as a change in the frequency of extreme fire weather events due to climate change. An inherent assumption is that the threshold values of $T_{\mathrm{G}}$ and $T_{\max }$ have the same physical significance under changed climate regimes. There are, however, a number of aspects that complicate the application of this technique to the climate models. Each model has a different resolution (see Table 1), and so the calculations cannot be performed on the same grid as the reanalyses, or on the same grid for each model, and there is no a priori reason to assume that the parameters simulated by the GCMs will have the same statistical distribution as the reanalyses. Accordingly, for each model the following steps were taken in order to have a basis for assessing the impact of climate change: (1) specification of gradient box bounds; (2) specification of latitude for $T_{\max }$ calculations; (3) specification of $T_{\mathrm{G}}$ and $T_{\max }$ thresholds; and (4) comparison of the $T_{\mathrm{G}} / T_{\max }$ distribution for C20C with the NNR and ERA-40 distributions. Only general descriptions of these steps are given in the following sections. Full details can be found in Hasson et al. (2008). 


\subsection{Specification of bounds of the gradient box for each model}

Table 1 shows the range of grid spacings of the climate change models used in the present study; none have the $2.5 \times 2.5^{\circ}$ spacing of the reanalyses. Accordingly, careful decisions were needed when selecting the appropriate gradient box and the latitude on which $T_{\max }$ was calculated for each model.

The size of the each individual gradient box was chosen to be as close as possible to the bounds used for the reanalyses (see Fig. 1). In most cases this resulted in slightly larger geographic areas, but not necessarily a larger number of gridpoints. While the east-west and north-south dimension of the reanalysis gradient box was $12.5 \times 5^{\circ}$, these varied between the climate change models from 11.1 (IPSL) to 15.0 (GFDL, GISSR) degrees longitude and 7.4 (CCM) to 8.4 (MRI) degrees latitude (Table 3).

\subsection{Specification of $T_{\max }$ latitude for each model}

Selection of the latitude at which to calculate $T_{\max }$ was often ambiguous due to the varying relationships between the selected gradient box, the grid resolution and the particular land-sea mask used in each model. Accordingly, for each model, scatter plots similar to Figs. $3 \& 4$ were constructed for $T_{\max }$ calculated on the latitude that was closest to the $37.5^{\circ}$ used for the reanalyses, and also using the next lower (equatorward) latitude row. The next higher latitude was not tested as it was generally located over the ocean south of the modelled continent. The distribution of the points in these diagrams varied, and for each model the latitude for which the slope of the trend-line was closer to that based on the NNR analyses was selected, although it must be acknowledged that the correlations, and thus the statistical significance of these slopes, are very low. This choice, though, did select those latitudes that showed a tendency for higher temperatures at the higher range of $T_{\mathrm{G}}$. The selected latitudes ranged from 38.0 (GISSR) to $34.2^{\circ} \mathrm{S}$ (IPSL) (Table 3). All scatter plots and a listing of the 2 latitudes for each model are found in Hasson et al. 2008.

\subsection{Specification of thresholds}

Inspection of the scatter plots in Hasson et al. (2008) shows consider- able variation in apparent distribution, together with considerable range in absolute values, which may be partly due to the normal latitudinal variation in temperature and partly to the differing latitudes used in the calculations. The approach to threshold specification used with the reanalyses cannot be used, as the climate models do not simulate actual events during the C20C period, and so statistical methods were used. A technique that determined approximately the same number of events per year for each model for the C20C was required, and after several approaches were tested (details in Hasson et al. 2008) the thresholds were specified based on the percentage of events that exceeded the $T_{\mathrm{G}}$ and $T_{\max }$ thresholds in the NNR data set. The data presented in Fig. 4 shows that $1.13 \%$ of days exceeded the $T_{\mathrm{G}}$ threshold of $3.2 \mathrm{~K} 100 \mathrm{~km}^{-1}$ and $28.39 \%$ of days exceeded the $T_{\max }$ threshold of $290 \mathrm{~K}$. Applying thresholds based on these percentages to each of the climate models and to the ERA-40 reanalysis in turn gave numbers of events in the $\mathrm{C} 20 \mathrm{C}$ period ranging between 12 (IPSL and GFDL1) and 32 (MPI). These numbers can be compared with the reanalysis numbers of 27 (NNR) and 28 (ERA-40). The individual thresholds and numbers of events for each model are listed in Table 3.

\section{EVALUATION OF C20C SIMULATIONS}

Before addressing future climates, this section makes some comparisons between the $\mathrm{C} 20 \mathrm{C}$ simulations of the $T_{\mathrm{G}} / T_{\max }$ phase space and the same distributions from each set of reanalyses, and a broad assessment of the models is made on the assumption that those that best simulate the reanalysis phase space for their $\mathrm{C} 20 \mathrm{C}$ simulations may be more reliable in their

Table 3. Maximum temperature gradient $\left(T_{\mathrm{G}}\right)$ and maximum temperature $\left(T_{\max }\right)$ threshold values and number of cases where the thresholds are jointly exceeded for each model, together with the selected latitude for the $T_{\max }$ calculation and the dimensions of the gradient box for each model. C20C: climate of the 20th century

\begin{tabular}{|lccccc|}
\hline Model & $\begin{array}{c}\text { Gradient box } \\
\left(\text { Long } \times \text { Lat }^{\circ}{ }^{\circ}\right)\end{array}$ & $\begin{array}{c}\text { Selected } \\
\text { latitude }\left(^{\circ}\right)\end{array}$ & $\begin{array}{c}T_{\max } \text { threshold } \\
\left(\mathrm{K} 100 \mathrm{~km}^{-1}\right)\end{array}$ & $\begin{array}{c}T_{\mathrm{G}} \text { threshold } \\
(\mathrm{K})\end{array}$ & $\begin{array}{c}\text { No. events } \\
(\mathrm{C} 20 \mathrm{C})\end{array}$ \\
\hline NNR & $12.5 \times 5.0$ & -37.5 & 3.20 & 290.0 & 27 \\
ERA-40 & $12.5 \times 5.0$ & -37.5 & 3.53 & 289.6 & 28 \\
MPI & $13.3 \times 7.6$ & -34.5 & 3.66 & 291.5 & 32 \\
MIROC & $14.0 \times 8.4$ & -34.9 & 2.82 & 286.7 & 19 \\
IPSL & $11.1 \times 7.5$ & -34.2 & 3.15 & 286.2 & 12 \\
GFDL1 & $15.0 \times 8.0$ & -35.0 & 4.63 & 292.1 & 12 \\
CNRM & $14.0 \times 8.4$ & -37.7 & 2.29 & 283.1 & 15 \\
GFDL2 & $15.0 \times 8.0$ & -35.4 & 4.06 & 289.4 & 22 \\
MRI & $14.0 \times 8.4$ & -37.7 & 2.96 & 285.6 & 23 \\
CCM & $11.4 \times 7.4$ & -35.3 & 2.62 & 286.7 & 22 \\
GISSR & $15.0 \times 8.0$ & -38.0 & 2.65 & 289.0 & 25 \\
CSIRO & $13.3 \times 7.6$ & -34.5 & 3.20 & 289.5 & 27 \\
\hline
\end{tabular}


simulations of future climates. Although hard to prove, it is an assumption often made when evaluating projections from climate models (CSIRO \& Bureau of Meteorology 2007, Whetton et al. 2007). The means and variances of the $T_{\mathrm{G}}$ and $T_{\max }$ distributions are first compared, and Fig. 5 shows the differences between the means and variances of the $T_{\mathrm{G}}$ distributions from that of the NNR. The differences between the means and variances of the 2 reanalyses provide some measure of the uncertainty of truth. We arbitrarily considered that a model's simulation of the C20C was close to that of the reanalyses if the value of its mean $T_{\mathrm{G}}$ was between those of the 2 reanalyses (dashed lines in Fig. 5), and a model was considered satisfactory if its mean was within the range delimited by the reanalyses' means plus or minus their difference (i.e. between -0.31 and $+0.62 \mathrm{~K}$ $\mathrm{km}^{-1}$; the dotted lines in Fig. 5). Models with means outside these bounds were considered distant. On this basis, MRI, CSIRO and GISSR models were close, MPI, MIROC, IPSL, CNRM and CCM models were satisfactory and GFDL1 and GFDL2 models were distant.

It is difficult to apply the same methodology to the difference between the variances of the climate models and the variance difference between NNR and ERA-40, as this latter difference $(\Delta=0.012)$ is very small. It was decided to consider a model as having a distant $T_{\mathrm{G}}$ distribution if the variance difference was $>50 \%$ of the NNR variance, i.e. 0.157 . This test adds the CNRM model to those considered distant, and the GFDL1 model is rated distant on this, as well as the previous test.

Earlier in this paper the trend-line slope of the scatter plots of $T_{\mathrm{G}}$ versus $T_{\max }$ was used to select the latitude at which $T_{\max }$ was calculated. There is still, however, considerable variation in this slope from model to model (Hasson et al. 2008, their Fig. 20 \& Appendix). In Fig. 6 the difference of the slopes of the trend-lines in those scatter plots is compared with the difference between the NNR and ERA-40 trend-line slopes. Applying a methodology analogous to that based on $T_{\mathrm{G}}$ (Fig. 5), and using the same conventions, classes the MIROC, CNRM, and GISSR models distant, while the GFDL1, GFDL2, CCM and CSIRO models are classed close.

Simple statistical tests such as the comparison of mean and standard deviation do not explore the entire data distribution, and indeed the accurate reproduction of the mean and variance of $T_{\mathrm{G}}$ does not necessarily show that the model probability density functions (PDFs) have reliable higher order moments. However, it is perhaps these higher order moments that are more important for the extreme events that are the focus of this investigation. Consequently, an attempt was made to use higher-level statistical tests to strengthen our evaluation of the models. Two tests, both based on the whole data PDFs, were performed for our model evaluation

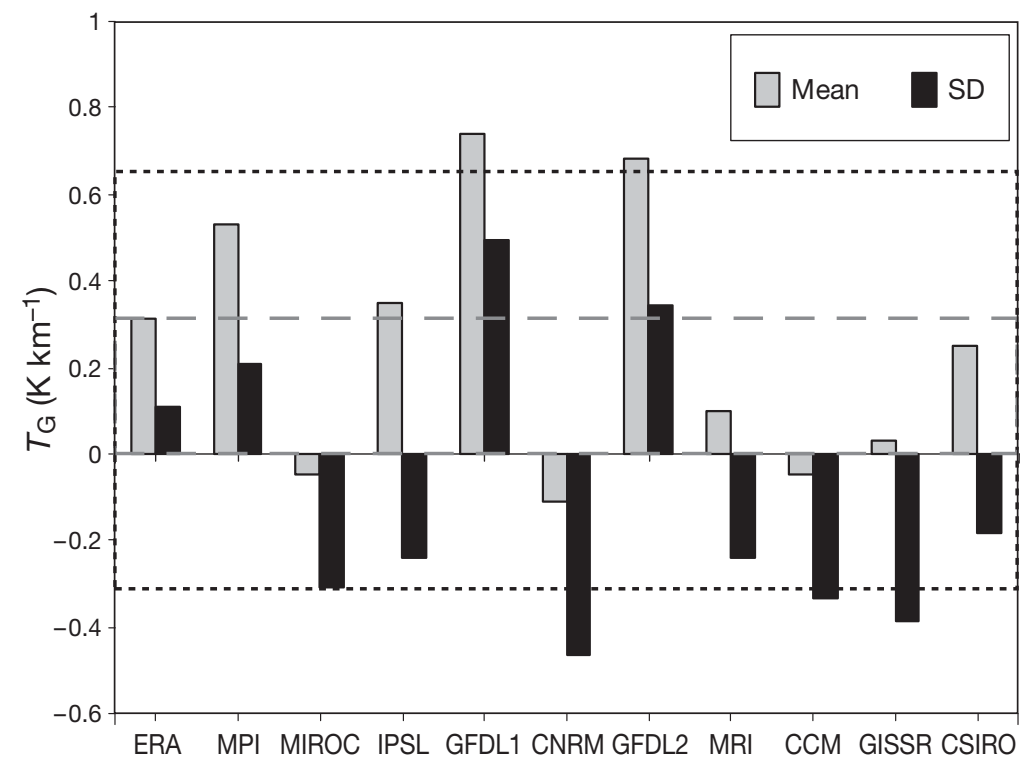

Fig. 5. Difference between the mean and SD of NNR maximum thermal gradient $\left(T_{\mathrm{G}}\right)$ values and those of ERA-40 and the climate models. The boundary between values of close and satisfactory models is shown by the dashed rectangle and between satisfactory and distant models by the dotted rectangle

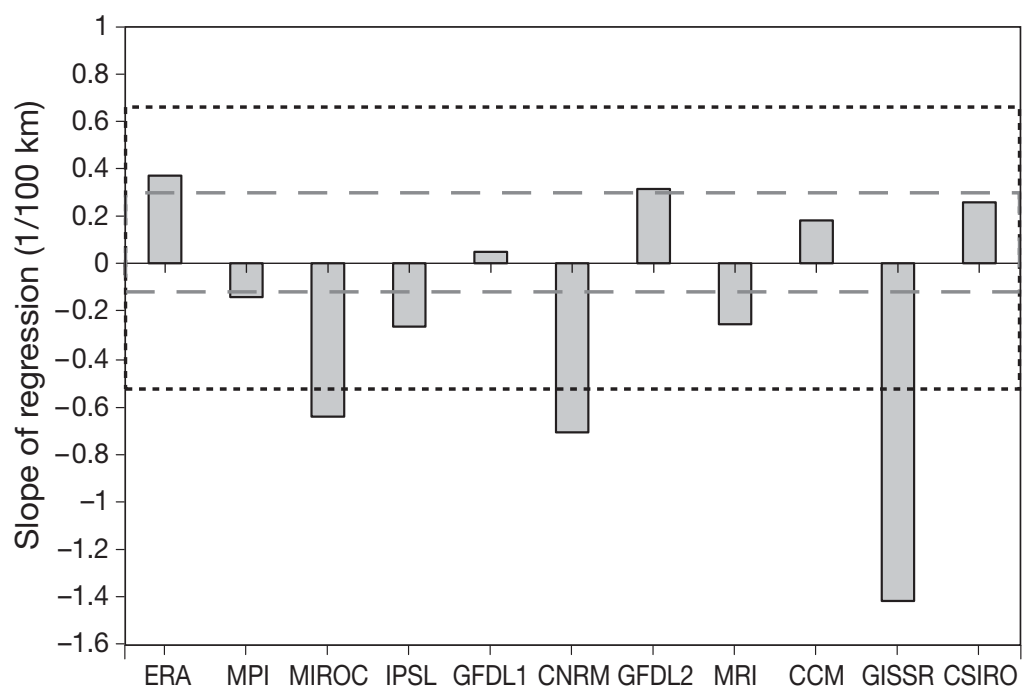

Fig. 6. Difference between the slopes of the linear regressions of the scatter plots for the climate models and that of the NNR scatter plot. The dashed and dotted rectangles have the same significance as in Fig. 5 
analysis: the Kolmogorov-Smirnov (KS) test (Wilks 1995) and a recent test proposed by Perkins et al. (2007). These test the model PDFs against the PDFs of the reanalyses, using the difference between the reanalyses as an estimation of the uncertainty.

The KS test is used to assess by how much the models' PDFs differ from those of the reanalyses. Unlike most goodness-of-fit tests, this test makes no assumptions about the distribution of the data. The KS test computes the $D$-statistic, which is the maximum vertical deviation between the cumulative fraction plots of 2 sets of data, and assesses the differences in shape and location of the cumulative distribution functions of the 2 data sets. The best skill score for the KS test corresponds to the smallest value of its $D$-statistic. Due to the dependence of the $T_{\max }$ distribution on latitude (see above), the KS test was only applied to the maximum temperature gradient $\left(T_{\mathrm{G}}\right)$ distributions over the defined gradient boxes, using the $\mathrm{R}$ statistical package. The $D$-statistic has been calculated with respect to both reanalyses and therefore the test gives 2 values per model (Fig. 7).

The KS test was also used to compare the 2 reanalysis data sets, resulting in a $D$-statistic of 0.18 ; this value is used for reference in the climate model comparison. Much of the difference between the 2 reanalyses lies in the different modes of the distributions, with the modes of the NNR and ERA-40 distributions being 1.3

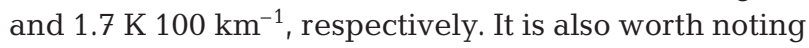
that the correlation between the $2 T_{\mathrm{G}}$ time series is considerably stronger in the post-satellite period from 1979 (40\% explained variance for $1964-1978,62 \%$ for 1979-2002). Averaging the 2 D-statistics for each model (numbers and curve in Fig. 7) provides a basis on which each model can be compared with the reanalysis $D$-value, $D_{\text {era }}$. In this assessment those models whose $D$ value is lower than $D_{\text {era }}$ (MRI, CSIRO, CCM and MIROC) are regarded as close, while those whose $D$-value is $>1.5$ times $D_{\text {era }}$ (GFLD1, GFLD2 and MPI) are classed as distant. Models whose $D$-values lie between these limits (CNRM and IPSL) are considered satisfactory.

Stating that 'it is not clear how to sum across [...] PDF-based statistics', Perkins et al. $(2007$, p. 4326) proposed an alternative way to objectively assess the ability of models to reproduce PDFs of selected observed parameters by measuring the common area under the PDFs of control and test data sets. This test gives each model a skill score (SS), with an SS of 1 indicating 2 identical frequency distributions. The SS is defined as:

$$
\mathrm{SS}=\sum_{1}^{n} \min \left(Z_{\mathrm{m}}, Z_{\mathrm{o}}\right)
$$

where $n$ is the number of bins used to calculate the PDF for a given region, $Z_{\mathrm{m}}$ is the frequency of values in a given bin from the model and $Z_{\mathrm{o}}$ is the frequency of values in a given bin of observed data. Considering the reanalyses to be 2 equivalently plausible versions of the observed data, 2 SSs were computed for each model (Fig. 8), where the models' average SS have been ranked in increasing order. There are no particularly obvious break points in this series, but if the reanalyses' SS of 0.83 is used as a criterion for classing a particular model as close, then MRI, CSIRO, CCM and MIROC meet this criterion, while GFDL1, GFDL2 and CNRM models are distant.

Interestingly, apart from exchanging the positions of the CNRM and MPI models, the ordering of the models is the same using both the KS and the Perkins tests (Figs. 7 \& 8). The simple tests, based on mean and variance, and the higher order tests result in a very similar ranking of the models, with CCM, CSIRO and MRI models consistently being close, and the CNRM, GFDL1 and GFDL2 models consistently distant. (It must be acknowledged that the KS and Perkins tests are applied to the whole data distribution, and so do not test purely the upper tails of the distributions.) Although this assessment is rather arbitrary, it does assist the interpretation of the results from future climate scenarios in the following section. In these future climate scenarios, all models are included but are differentiated based on these assessments in order to better describe the uncertainty attached to the future projections for these extreme weather events.

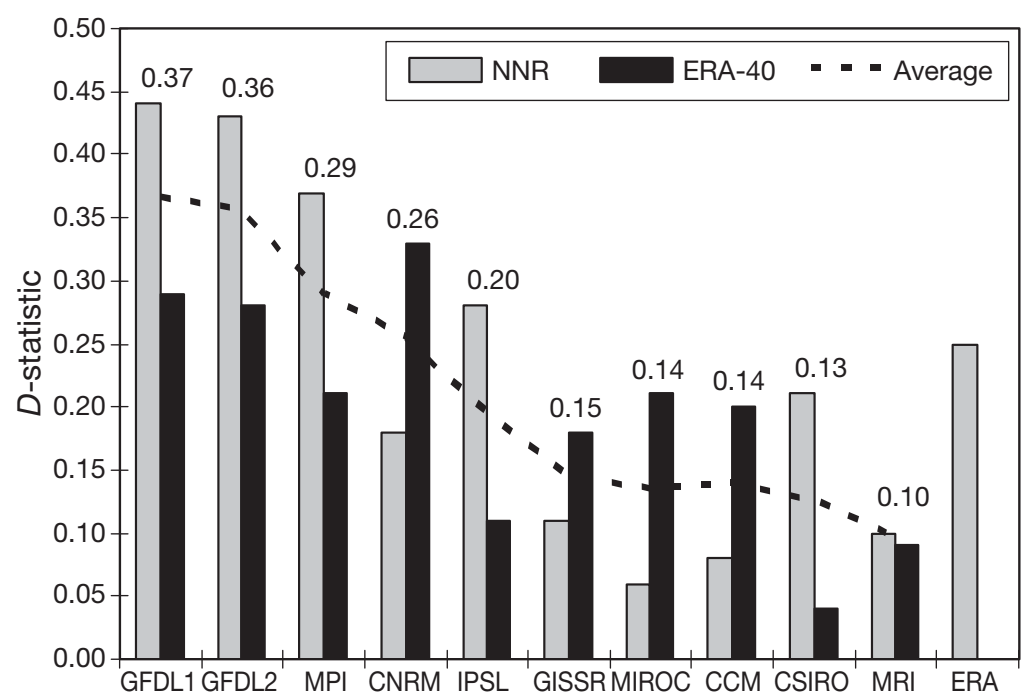

Fig. 7. Kolmogorov-Smirnov (KS) test results ( $D$-statistic) for each of the climate models using both NNR and ERA-40 as control sets. The average values are linked by a dashed curve. Gray ERA bar: the KS test comparing the ERA-40 with the NRR reanalysis 


\section{PROJECTED CHANGES DURING THE 21ST CENTURY}

In this section the changes in the number of strong cold front days under the B1 and A2 SRES scenarios for two 20 yr periods centered on 2050 and 2090 are examined. This analysis assumes that the thresholds defining an extreme fire day will remain unchanged; therefore, any changes in the number of days on which both $T_{\mathrm{G}}$ and $T_{\text {max }}$ thresholds are exceeded equate to changes in frequency of these extreme fire weather frontal passages.

As an example, Fig. 9 shows the scatter plot of $T_{\mathrm{G}}$ versus $T_{\max }$ under the climate change scenarios from the MRI model. Displayed are the results for the 20th century (blue dots) and the A2 scenario (strongest heating) for the 2081-2100 period (orange dots). The trend lines for the $\mathrm{C} 20 \mathrm{C}$ and the $\mathrm{B} 1$ and A2 scenarios for the middle (2046-2065) and end (2081-2100) of the 21 st century are overlayed. The slopes of all trendlines are virtually identical, but each line is displaced to higher temperatures consistent with the simulated average warming under the under the different emissions scenarios and time extrapolations. It should be noted that there is also a larger number of high $T_{\mathrm{G}}$ values under the more extreme scenario (orange dots).

In Fig. 10 the percentage change in number of extreme frontal systems for the assessment periods in the middle and end of the 21st century are shown for the 3 models (MRI, CCM and CSIRO) deemed in the previous section to be consistently closest to the reanalyses' climate. These 3 models all show an increase in the occurrence of the class of extreme fire weather events as defined in the present study over the 21 st century, although there is considerable difference in

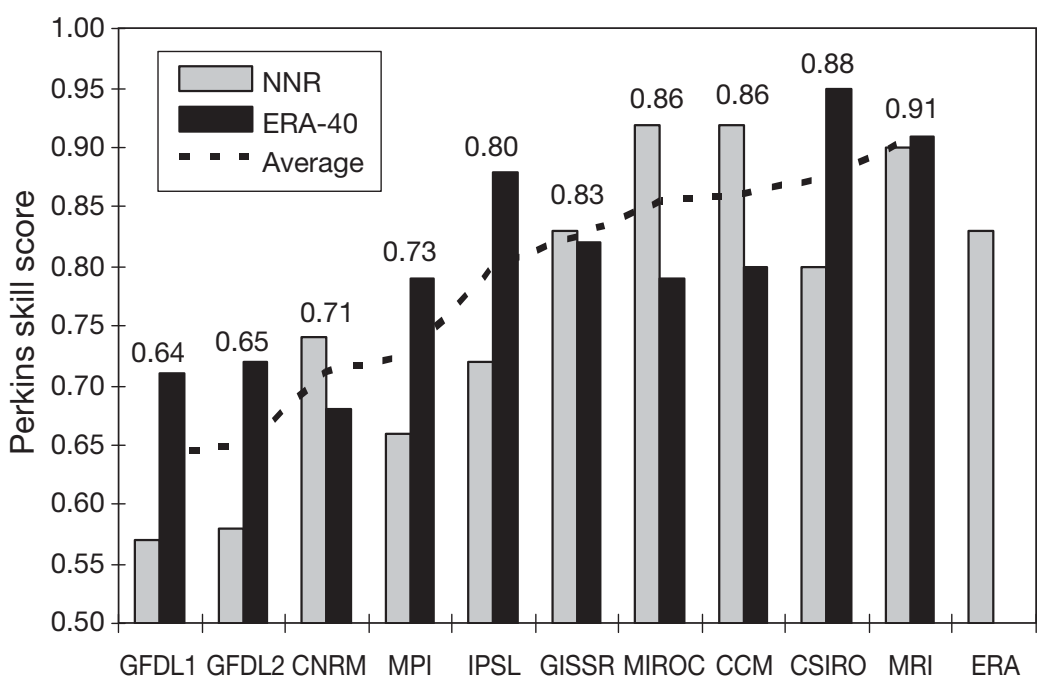

Fig. 8. Results of the skill score (SS) test (Perkins et al. 2007) for each climate model using both NNR and ERA-40 as control sets. Average values are linked with a dashed curve. Gray ERA bar: the SS test comparing the ERA-40 with the NRR reanalysis the amplitude of the signal between the 2 scenarios. Under the B1 scenario, all 3 models show an increased frequency of extreme events by the middle of the $21 \mathrm{st}$ century. This frequency then declines slightly towards the end of the 21st century, but still ranges between 13 and $99 \%$ greater than during the late 20th century. Under the A2 scenario, there is a change of between -25 and $102 \%$ by the middle of the 21 st century, and an increase of between 77 and $312 \%$ by the end of the 21 st century.

While the projections from these 3 models might be hypothesized to be more reliable than the other models, there is a need to assess the uncertainties attached to these future projections, as their application to extreme events, such as the intense frontal systems dealt with in the present study, remains unproven. Given the spread of results between models in Fig. 10, there is value in presenting the projected changes for all the available climate models in order to better interpret the uncertainties already present between the closest models. Such changes for all 10 models are shown in Fig. 11 for the B1 and A2 scenarios in terms of number of events per year. The 3 models whose climates are closest to the reanalyses are in bold, and the 3 whose climates are most distant are shown with dashed lines. For the B1 scenario, there is considerable qualitative consistency in the projections, with all models showing an increase in the number of events per year during the first half of the 21st century, and all but one (IPSL) then either showing a decrease, or a substantially lower rate of increase, in numbers towards the end of the 21st century, but with an increasing spread in the potential numbers. Under the A2 scenario, all but 2 models show an increase in the number of events during the first half of the 21st century and an even greater increase in the next $50 \mathrm{yr}$. Even if the IPSL model (the model showing the most extreme rate of increase) is excluded, the mean number of events per year changes from 0.59 (C20C) to 0.93 (1.04) by the middle of the 21st century for the B1 (A2) scenarios, and to 0.94 (1.54) by the end of the 21st century.

The projected changes in strong frontal frequency (Fig. 11) do not appear to be related to the climate model sensitivity shown earlier (Table 1). For example, the CSIRO model is the least sensitive in terms of mean global warming but shows the largest change in number of extreme cold fronts under the B1 forcing scenario, while the second most sensitive model (MIROC) shows the lowest A2 signal in terms of change in the number of strong cold fronts. These associations suggest that the changes in strong frontal frequency do not relate to the model's global sensitivity. 


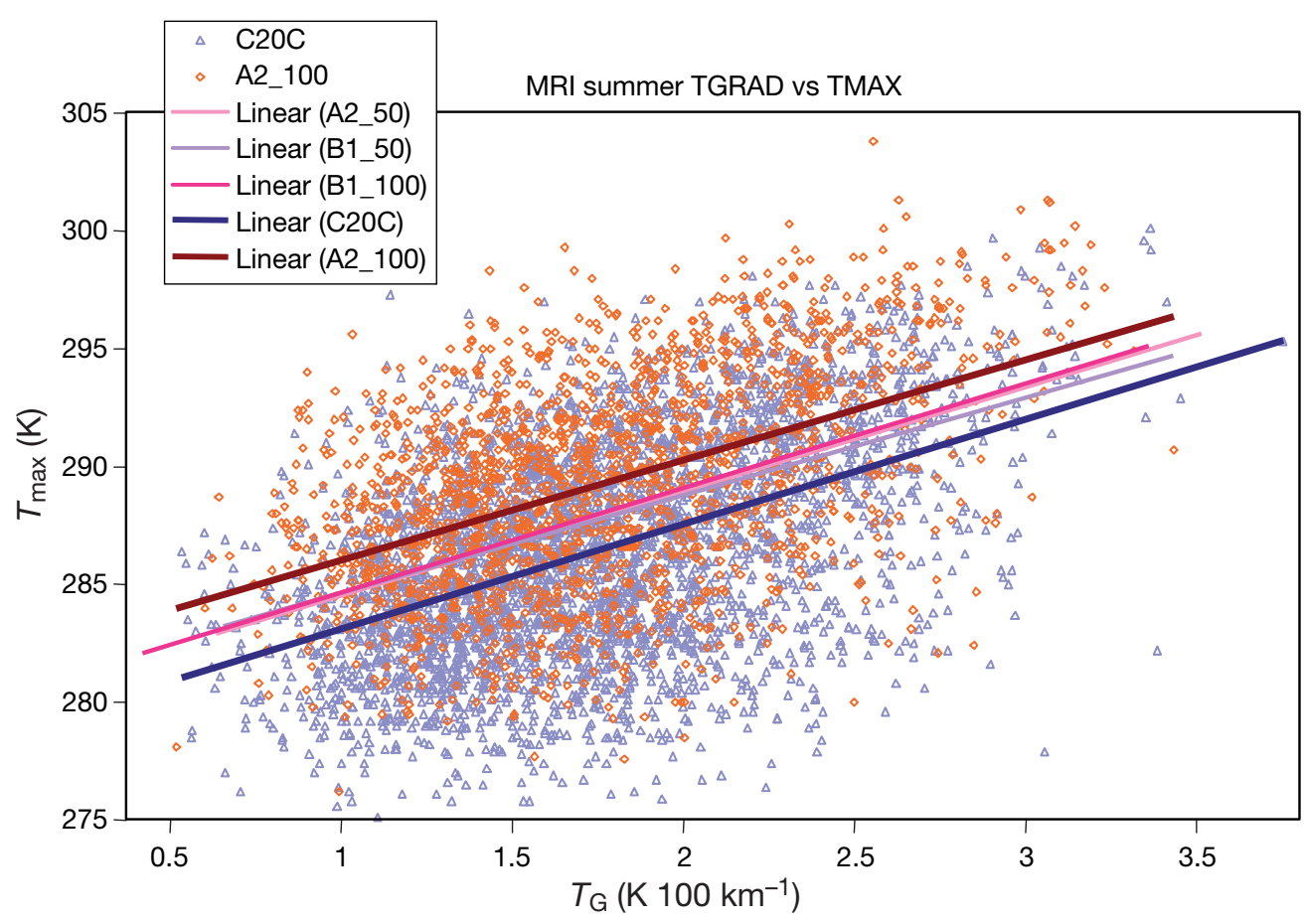

Fig. 9. As Fig. 3 but for the MRI model C20C (blue dots). Values for the period 2081-2100 are displayed as orange dots. Linear regressions for the period 1964-2000 and for the high and low emissions scenarios over the periods 2046-2065 (A2_50 and B1_50) and 20812100 (A2_100 and B1_100) are also shown

\section{DISCUSSION}

The $850 \mathrm{hPa}$ maximum temperature/temperature gradient phase space that Mills (2005a) suggested discriminates the environments of the most extreme fire weather cold fronts over southeastern Australia has been applied to NNR and ERA-40 reanalyses, and to the output of $10 \mathrm{GCMs}^{\prime}$ simulation of both the climate of the late 20th century and their simulations of climates in the middle and late 21 st century. It was shown that the 00:00 UTC data available from climate models from the CMIP3 data set were sufficient to discriminate these events.

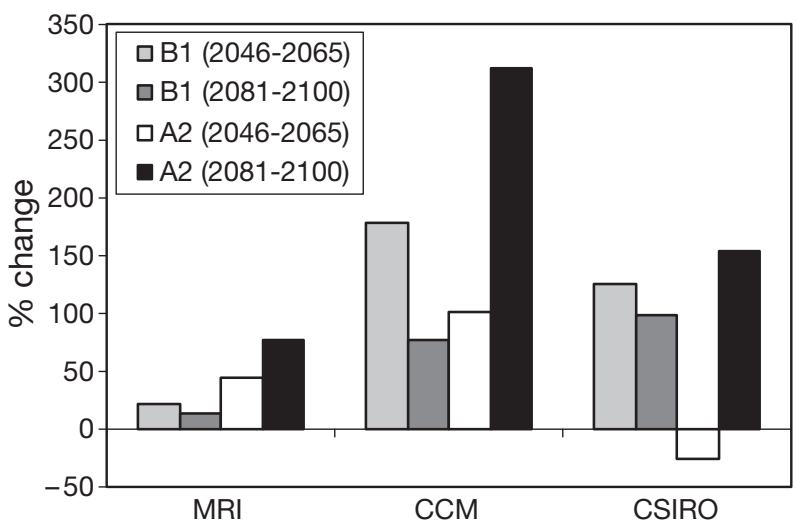

Fig. 10. Percentage change in the number of extreme cases per decade from the 20th century to the periods 2046-2065 and 2081-2100 for the low and high emissions scenarios for the 3 models whose 20th century climate is closest to that of the reanalyses
However, the application to climate models required careful selection of target areas and latitudes due to their varying grid resolutions and careful evaluation of their simulations of the 20th century climate. As any changes in frequency in the extreme cold frontal synoptic paradigm under climate change scenarios are dependent on the exceedences of temperature and temperature gradient thresholds, the selection of these threshold values is an important decision, and is model-dependent since the models' C20C climates are different to those of the reanalyses. In the present study, thresholds based on the percentage of exceedences in the $\mathrm{C} 20 \mathrm{C}$ being the same as those percentages in the reanalyses was used. While Hasson et al. (2008) tested some alternative approaches, these were found to be less satisfactory than the approach used, but other techniques should be explored in the future.

When applied to climate simulations of time-slices in the middle and the end of the 21st century, an increasing frequency of strong cold frontal events under climate change conditions are indicated for the 2 forcing scenarios investigated. Under both the low and high emissions scenarios, the models used in the present study show a general increase, but with very large uncertainty, in the annual frequency of extreme frontal fire weather events by the end of the 21st century. Excluding the one model that showed a far stronger trend than the others, the increases amount to a change from around 1 event every 2 yr during the 20th century to around 1 event per year in the middle of the 21 st century, and 1 to 2 events per year by the end of 


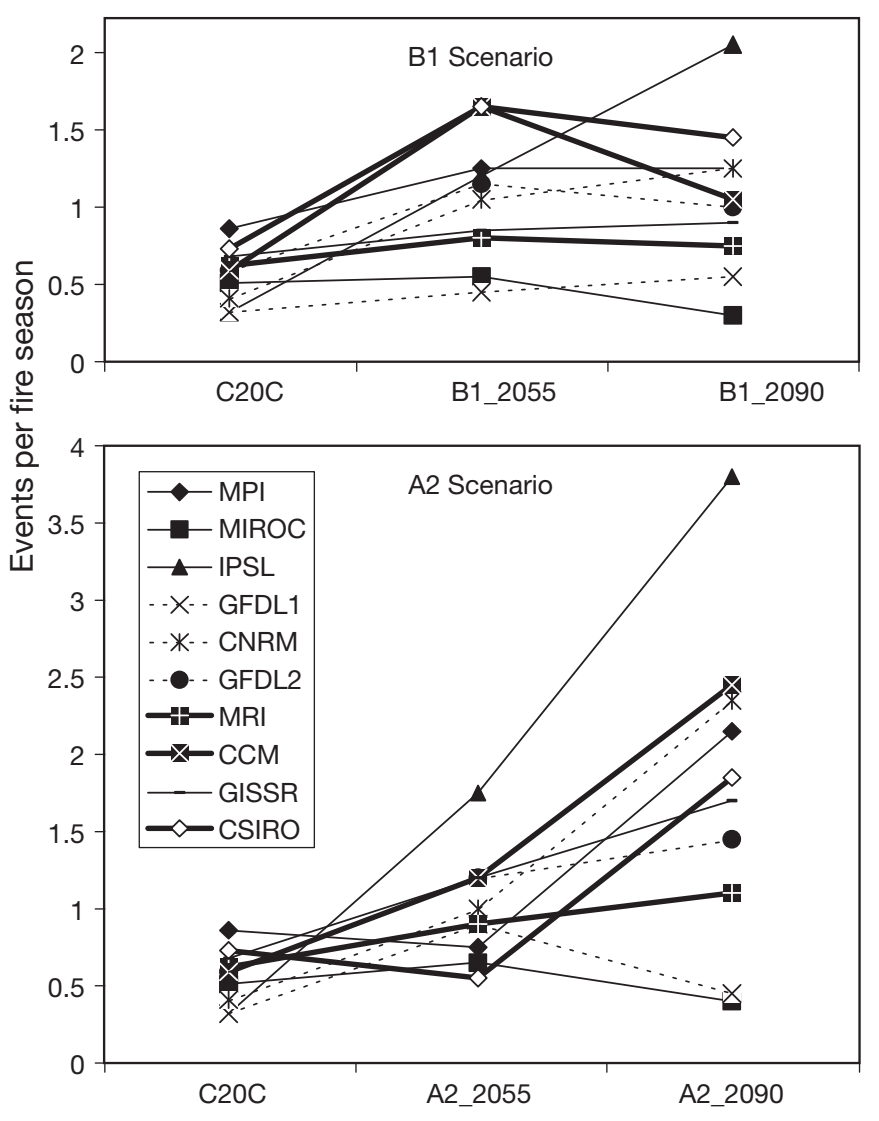

Fig. 11. Number of extreme fire weather frontal events per season for the climate of the 20th century (C20C) and the 2046-2065 (B1_2055 and A2_2055) and the 2080-2100 periods (B1_2090 and A2_2090). Upper panel shows projections for the B1 emissions scenario, and the lower panel for the A2 scenario. The heavy lines are for the 3 close models, the dashed lines are for the 3 distant models and the thin solid lines are for the 4 satisfactory models

the 21st century; however, there is a great degree of variation between models. Interestingly, there appears to be little relation between the global mean temperature increases indicated by each model and the projected changes in the number of extreme cold frontal events indicated by our analysis, suggesting that diagnosis of the type applied in the present study is complementary to analyses of changes based on mean global warming statistics. It is also interesting to note that in addition to a greater overall increase under the high emissions scenario, the rate at which the increase occurs amplifies during the second half of the century, whereas under the low emissions scenario the number of extreme cases stabilizes. However, since no relationship is apparent between global temperature increase (which is higher with the A2 than the B1 emissions scenario) and extreme cold front occurrence, it is a reasonable hypothesis that the difference between the 2 scenarios is due to the different forcing and warming rates. The difference in the overall increase of the number of extreme danger episodes between the 2 emissions scenarios, and between the different models, should be taken in account when interpreting the large relative increases that some models predict by the end of the 21st century under the high emissions scenario.

Previous studies (Hennessy et al. 2005, Lucas et al. 2007) investigated the evolution of occurrence of extreme fire danger days through FFDI statistics for southeast Australia. Hennessy et al. (2005) found a potential increase of very high and extreme FFDI days by 15 to $70 \%$ by 2050 , based on 2 CSIRO fine (60 km) resolution climate models, scaled by IPCC (2001) global warming ranges for the full range of emission scenarios, including A1FI. Lucas et al. (2007) found a potential increase of 5 to $100 \%$ by 2050, using the same 2 CSIRO models scaled by the IPCC (2007) global warming ranges for the full range of emissions scenarios, including A1FI. In the present study, the focus has been on projected changes in the number of a particular type of synoptic weather pattern that has been shown to be associated with extreme fire weather events. Our conclusions that the GCMs indicate an increase in the frequency of such events, combined with the results of the studies based on FFDI, adds to the consensus regarding future increased fire danger in southeast Australia.

In the years since February 2002 there have been a number of disastrous fires in southeastern Australia, and Lucas et al. (2007) showed that these seasons show an extraordinary increase in the number of observed extreme fire danger days per season, as well as increases in the median FFDI for those seasons. Repeating this exercise with updated reanalysis data to include data to the end of the 2008-2009 summer, and with higher-resolution climate model data, would be a fruitful avenue for further research.

Acknowledgements. We acknowledge the Program for Climate Model Diagnosis and Intercomparison and the World Climatic Research Program's Working Group on Coupled Modelling for their roles in making available the WCRP CMIP3 multi-model data set. Support of this data set was provided by the Office of Science, US Department of Energy. A. Moise and L. Hanson provided invaluable assistance reading the data sets and their assistance is gratefully acknowledged. The constructive reviews provided by K. Hennessy and R. Colman improved the clarity of the paper.

\section{LITERATURE CITED}

Bond HG, McKinnon K, Noar PE (1967) Report on the meteorological aspects of the catastrophic bushfires in south-eastern Tasmania on 7 February 1967. Bureau of Meteorology, Melbourne

Bureau of Meteorology (1984) Report on the meteorological 
aspects of the Ash Wednesday fires - 16 February 1983. Bureau of Meteorology, Canberra

Bureau of Meteorology (2005) Meteorological report on the Wangary and Black Tuesday fires Lower Eyre Peninsula, 10-11 January 2005. Bureau of Meteorology, South Australian Regional Office, Kent Town

Cheney P, Gould J, McCaw L (2001) The Dead Man Zone: a neglected area of firefighter safety. Aust For 64:45-50

CSIRO (Commonwealth Scientific and Industrial Research Organisation), Bureau of Meteorology (2007) Climate change in Australia: technical report 2007. CSIRO Marine and Atmospheric Research, Aspendale, Victoria. Available from the Australian Greenhouse Office, www.climatechangeinaustralia.gov.au

Hasson AEA, Mills GA, Timbal B, Walsh K (2008) Assessing the impact of climate change on extreme fire weather in southeast Australia. Centre for Australian Weather and Climate Research, Melbourne. CAWCR Tech Rep 007, available at www.cawcr.gov.au/publications/technicalreports. php

Hennessy K, Lucas C, Nicholls JB, Suppiah R, Ricketts J (2005) Climate change impacts on fire-weather in south-east Australia. CSIRO and Bureau of Meteorology, Canberra

IPCC (Intergovernmental Panel on Climate Change) (2000) Emissions scenarios. Cambridge University Press, Cambridge

IPCC (2001) Summary for policymakers. In: Houghton JT, Ding Y, Griggs DJ, Noguer M, Van Der Linden PJ, Xioaosu D (eds) Climate Change 2001: the scientific basis. Contribution of Working Group I to the Third Assessment Report of the Intergovernmental Panel on Climate Change. Cambridge University Press, Cambridge

IPCC (2007) Climate Change 2007: the physical science basis. Contribution of Working Group I to the Fourth Assessment Report of the Intergovernmental Panel on Climate Change, Cambridge University Press, Cambridge

Kallberg P, Berrisford P, Hoskins B, Simmons A, Uppala S, Lamy-Thepaut S, Hine R (2005) ERA-40 Atlas, ERA-40 Project Report Series, No 19. European Centre for Medium Range Weather Forecasts, Reading

Kalnay E, Kanamitsu M, Kistler R, Collins W and others (1996)

Editorial responsibility: Balaji Rajagopalan,

Boulder, Colorado, USA
The NCEP/NCAR 40-year reanalysis project. Bull Am Meteorol Soc 77:437-471

Lucas C, Hennessy K, Mills G, Bathols J (2007) Bushfire weather in southeast Australia: recent trends and projected climate change impacts. Consultancy Report prepared for the Climate Institute of Australia. Bushfire Cooperative Research Centre, East Melbourne

Luke RH, McArthur AG (1978) Bushfires in Australia. Australian Government Publishing Service, Canberra

McLeod RN (2003) Inquiry into the operational response to the January 2003 bushfires in the ACT. Department of Urban Services, Canberra

Mills GA (2005a) A re-examination of the synoptic and mesoscale meteorology of Ash Wednesday 1983. Aust Meteorol Mag 54:35-55

Mills GA (2005b) On the sub-synoptic scale meteorology of two extreme fire weather days during the Eastern Australian fires of January 2003. Aust Meteorol Mag 54: 265-290

Mills GA (2008) Abrupt surface drying and fire weather. Part 1: overview and case study of the South Australian fires of 11 January 2005. Aust Meteorol Mag 57:299-309

> Perkins SE, Pitman AJ, Holbrook NJ, McAneney J (2007) Evaluation of the AR4 climate models' simulated daily maximum temperature, minimum temperature, and precipitation over Australia using probability density functions. J Clim 20:4356-4376

Pitman AJ, Narisma GT, McAneney J (2007) The impact of climate change on the risk of forest and grassland fires in Australia. Clim Change 84:383-401

Whetton P, Macadam I, Bathols J, O'Grady J (2007) Assessment of the use of current climate patterns to evaluate regional enhanced greenhouse response patterns of climate models. Geophys Res Lett 34:L14701, doi: 10.1029/ 2007GL030025

Wilks DS (1995) Statistical methods in the atmospheric sciences. International Geophysics Series, Vol 59. Academic Press, San Diego, CA

> Williams AAJ, Karoly DJ, Tapper N (2001) The sensitivity of Australian fire danger to climate change. Clim Change 49:171-191

Submitted: November 22, 2008; Accepted: May 26, 2009

Proofs received from author(s): August 3, 2009 